\title{
Dynamic Thiol/Disulphide Homeostasis as Oxidative Stress Marker in Ankylosing Spondylitis and Undifferentiated Spondyloarthropathy
}

\begin{abstract}
Background/aim: Seronegative spondyloarthropathies $(\mathrm{SpA})$ are a group of chronic diseases, characterized by axial inflammation, oligoarthritis, and enthesitis. Oxidative stress may contribute to a wide range of diseases such as rheumatologic diseases including SpA. This prospective case-control study was designed to compare the thiol-disulfide levels as a marker of oxidative stress in SpA patients with healthy controls.
\end{abstract}

Materials and methods: A total of 144 patients who were diagnosed as undifferentiated spondyloarthropathy (UspA, $n=97$ ), ankylosing spondylitis (AS, $n=47$ ), and 80 healthy controls were included. Serum native thiol (NT), total thiol (TT), disulfide (D) levels were measured with the fully automated Erel's method. NT/TT, D/TT, and D/NT ratios were calculated. Thiol-disulfide levels were compared between SpA groups and healthy controls.

Results: NT and NT/TT ratios were found to be significantly lower in the SpA group. ( $\mathrm{p}<0.001$ ). Disulfide, $\mathrm{D} / \mathrm{NT}$, and $\mathrm{D} / \mathrm{TT}$ ratios were found to be significantly higher in the SpA group ( $\mathrm{p}<0.001$ for each comparison). In pairwise comparisons between SpA subgroups, NT and TT levels were lower in USpA group compared to AS group $(\mathrm{P}=0.021)$. Serum disulfide levels were higher in USpA group compared to AS group $(\mathrm{P}=0,004)$. Anti-tumor necrosis factor (Anti-TNF) group had lower TT measurements compared to the classical disease modifying anti-rheumatic drugs (cDMARD) group in patients with $\mathrm{SpA}(\mathrm{P}=0.039)$. 
1 Conclusion: Thiol-disulfide balance is disturbed in favor of disulfide in SpAs patients

2 compared to healthy volunteers. Native and total thiol measurements correlate with acute

3 phase reactants and might be used to monitor disease activity. Anti-TNF therapy might

4 control the oxidative degenerative process better than the classical DMARD in SpA

5 patients.

6 Keywords: Ankylosing spondylitis, spondyloarthropathy, thiol, disulfide, oxidative 7 stress, tumor necrosis factor-a (TNF-a) antagonist.

\section{Introduction}

9 Seronegative spondyloarthritis ( $\mathrm{SpA})$ is a chronic disease that mostly presents with axial inflammation, oligoarthritis, enthesitis, uveitis, and less likely with dactylitis, erythema nodosum, and enteral involvement. Subgroups of the SpA consist of ankylosing spondylitis (AS), undifferentiated spondyloarthritis (USpA), enteropathic arthritis, reactive arthritis (ReA), psoriatic arthritis, and juvenile spondyloarthritis.(1)

Reactive oxygen spices (ROS) are often synthesized due to physiologic mechanisms such as aerobic metabolism, nitric oxide (NO) synthesis, and also pathologic mechanisms such as malignancy, smoking, infections, and rheumatologic conditions.(2) Excessive ROS production that cannot counterbalance with redox buffer capacity may lead to cellular damage.(3) Oxidative stress is mainly controlled by thiols, also known as mercaptans which play an essential role as a radical scavenger.(4) Thiols consist of the main compound of anti-oxidation pool in human metabolism. Thiols form reversible disulfide bridges via oxidizing ROS and are reduced to thiol groups again when conditions change in favor of antioxidants. There are several approaches for measuring oxidative stress in human metabolism which are mainly based on direct and indirect detection methods. 
1 Direct measurement of the free radicals such as hydrogen peroxide, oxygen singlet,

2 hypochlorite, and nitric oxide or the indirect measurement of the oxidative stress products

3 also called as redox biomarkers such as glutathione, dityrosine, 8-hydroxy-2'-

4 deoxyguanosine (8OHdG), thiol and disulfide can be performed.(5-7) Erel et al.

5 developed a novel technique to determine thiol and disulfide levels with high accuracy.(8)

6 Up to now, a number of studies have demonstrated that oxidative stress contributes to the

7 pathogenesis of chronic degenerative diseases and rheumatologic diseases including

8 SpA.(9-17) So far, the clinical significance of thiol-disulfide balance in patients with SpA

9 is understudied. The present study aims to test the difference in serum dynamic thiol-

10 disulfide levels with Erel's method amongst SpA patients and healthy controls and also

11 in two patient subgroups (USpA and AS patients). The secondary aim of the study is to

12 compare the dynamic thiol-disulfide levels of the two different treatment groups of the patients (anti-TNF versus cDMARD+NSAID).

\section{Materials and methods}

A total of 144 patients with AS and USpA and 80 healthy volunteers were included. All of the patients who were included in our study were admitted to our out-patient rheumatology department consecutively. All the eligible participants were above 18 years old. The diagnosis of AS and USpA was made according to the modified New York criteria and ASAS classification criteria for axial SpA.(18, 19). The patient group has been divided into two groups according to their treatment modality (Anti-TNF versus cDMARDs and NSAIDs) and also their disease subtype. 
1 Patients were excluded if they had a history of malignancy, smoking, another overlapping

2 rheumatic disease, liver and renal dysfunctions, or any other chronic diseases. The healthy control group had no known previous medical history of any chronic disease, smoking or additional substance use. The control group was selected in an age-and-gender-matched manner regarding to features of the patient group. Demographic characteristics of the patients and healthy controls were given in Table 1. The findings of physical examination, plain radiography of joints, and sacroiliac MR imaging (as needed) were evaluated in the patient group. BASDAI score was used to assess disease activity.(20) HLA B27 gene analysis was included in the analysis. Peripheral blood samples obtained from healthy volunteers and the patients were analyzed for native thiol (NT), total thiol (TT), and disulfide (D) levels. Concomitantly, complete blood count, erythrocyte sedimentation rate (ESR), C-reactive protein (CRP), and biochemical parameters merely evaluated in patient groups. Disulfide and thiol levels were measured by a novel fullyautomated colorimetric method developed by Erel and Neselioglu.(8) Disulfide/native thiol (D/NT), disulfide/total thiol (D/TT), and native thiol/total thiol (NT/TT) ratios were calculated. Patient and healthy control groups were compared in terms of demographic characteristics, laboratory findings, and NT, TT, disulfide levels and D/NT, D/TT, NT/TT ratios. USpA and AS groups were also compared regarding HLA B-27 positivity, disease activity scores, NT, TT, disulfide levels, and D/NT, D/TT, and NT/TT ratios.

Written informed consent was obtained from all participants. Ethical approval was obtained from our local ethics committee.

\subsection{Statistical analysis:}


1 Shapiro-Wilk test was used to determine whether the variables have parametric or non-

2 parametric distribution. Descriptive statistics of the data with normal distribution were

3 given as mean \pm standard deviation. Descriptive statistics of the variables, which have

4 non-normal distribution, were reported as median with data range (minimum to

5 maximum). Student T-test and Mann-Whitney $U$ test were utilized for pairwise

6 comparisons regarding parametric or non-parametric distribution of the continuous

7 variables. Levene's test is calculated for testing the homogeneity of the variances as

8 needed.

9 Kruskal Wallis test was utilized to compare the age variable between patient subgroups (AS and USpA) and control groups. One-way ANOVA test was applied to assess the variance analysis of the subgroups according to NT, TT, disulfide, D/NT, D/TT, and NT/TT ratios. In addition, since the gender variable was significantly different between the groups, NT, TT, disulfide values and D/NT ratio, D/TT ratio, NT/TT ratios were evaluated with the covariance analysis (one-way ANCOVA) test for eliminating gender effect. Post-hoc Bonferroni test was used for multiple pair-wise comparisons.

Mann's Whitney U test has been performed to compare the groups according to Bath (CRP), erythrocyte sedimentation rate (ESR) due to the non-parametric distribution of the parameters. Pearson correlation and Spearman correlation tests were applied to identify any association of $\mathrm{NT}$, TT, disulfide values, D/NT ratio, D/TT ratio and NT/TT ratios with Bath Ankylosing Spondylitis Disease Activity Index (BASDAI), age, C-reactive protein (CRP) and erythrocyte sedimentation rate (ESR). To compare categorical variables between groups, the Chi-square test is applied. IBM SPSS Statistics 21.0 has 
been used for statistical analysis. The level of statistical significance was accepted as $p$ $<0.05$.

\section{Results}

A total of 144 patients and 80 healthy volunteers were included in the study. In the patient group, $67 \%(n=97)$ of the patients had a diagnosis of USpA and $32 \%(n=47)$ of them had AS. The SpA group and the healthy group were similar according to gender $(p=0.167)$ and age $(\mathrm{p}=0.187)$ distribution. As expected, there was a male preponderance in AS group compared to USpA group ( $53 \%$ vs $17 \%, \mathrm{p}<0.001)$. The median age of patients in the AS group was 46 years (range: 28-66), 50 years in the USpA group (range: 23-66), 46 years in the control group (range: 24-72) (Table 1). There was no significant difference between AS and USpA groups regarding disease duration, age at the diagnosis, BASDAI, ESR, and CRP levels. (Table 2). HLA-B27 results were available in $45.8 \%(n=66)$ of the patients. Among the patients who had HLA-B27 analysis, 52.9\% (n=9) of the AS group and $30.6 \%(n=15)$ of the USpA group were found to be positive. As expected, HLA-B27 positivity was higher in the AS group but this was not reached a statistical significance $(\mathrm{p}=0.09)$.

Native thiol levels were significantly lower in the SpA group than in the healthy volunteer group. ( $\mathrm{p}<0,001$ ). Total thiol levels were also lower in the SpA group but it did not reach statistical significance $(\mathrm{p}=0.074)$. Disulfide levels, $\mathrm{D} / \mathrm{NT}$, and $\mathrm{D} / \mathrm{TT}$ were significantly higher in the SpA group than in the healthy control group $(\mathrm{p}<0.001) .(\mathrm{p}<0.001)$. On the other hand, NT/TT ratio was also significantly lower in SPA groups than in healthy 
control group $(\mathrm{p}<0.001)$. Details of the comparisons between groups in terms of thiol-

2 disulfide levels are shown in Table 3 and Table 4.

$3 \quad$ NT and TT levels were negatively correlated with CRP level $(r=-0.45, \mathrm{P}<0.001)$ and ESR

$4 \quad(r=-0.396, \mathrm{P}<0.001, r=-0.351, \mathrm{P}<0.001$, respectively $)$. Disulfide levels, D/NT , and D/TT

5 ratios were also negatively correlated with disease duration $(r=-0.196, \mathrm{P}=0,039, r=-0.192$,

$6 \mathrm{P}=0,043, r=-0.192, \mathrm{P}=0,043$, respectively). However, no correlation was found between

7 the BASDAI score and thiol-disulfide parameters. Results of correlation analysis between

8 variables such as BASDAI score, disease duration, CRP, and ESR, and dynamic thiol-

$9 \quad$ disulfide parameters are given in Table 5.

Patient subgroups according to treatment modality (Anti-TNF and conventional DMARD's) were compared in terms of NT and TT levels. TT levels were statistically lower in patients using anti-TNF agents compared to classical DMARD's. $(p=0.039)$. Details are showed in Table 6.

\section{Discussion}

In the present study, native thiol and native thiol/total thiol ratio were found to be significantly lower and disulfide, D/NT, and D/TT ratios were found to be significantly higher in SpA patients. In addition, native and total thiol levels were lower and serum disulfide levels were higher in USpA group compared to AS patients.

Recently, there has been a growing number of publications focusing on the relationship between oxidative stress with chronic diseases such as hypertension, asthma, cardiovascular diseases as well as rheumatologic diseases.(21-25) Thiols play a fundamental role in reducing oxidative stress and protecting from cellular damage by forming disulfide bridges with covalent bonds.(4) In this respect, the level of thiol in the 
1 body can be an important indicator of the antioxidant capacity of metabolism.

2 Consistently, in our study, serum thiol (native and total) levels were significantly lower in the SpA patients compared to the control group. Similarly, in a small group of patients,

Dogru et al. showed that native thiol and total thiol levels were significantly low in AS patients. They also reported a negative correlation between BASDAI and thiol levels.(22) In contrast, our study, which was based on a larger patient group, did not confirm the correlation between BASDAI and thiol levels. BASDAI score is based on a questionnaire and therefore may have subjective results. This may explain the lack of correlation between BASDAI and thiol-disulfide levels. In another study conducted to evaluate thioldisulfide balance in AS, also found that total thiol levels and N/TT ratio are lower in AS patients compared to healthy controls.(2) They did not find any significant correlation between DMARD and anti-TNF groups. Conversely, in our study anti-TNF group had higher total thiol levels that may imply anti-TNF therapy may control oxidative stress more effectively than conventional DMARD.

In this study, thiol levels were found to be significantly lower in USpA patients than in AS patients. In addition to that, NT and TT levels were not significantly different between the AS group and the healthy control. This may be explained by the widespread utilization of effective treatment modalities consisting of anti-TNF drugs in recent years. Ugan et al. reported that infliximab, an anti-TNF drug may protect against oxidative stress and apoptotic cell death in AS patients and also regulate the signal mechanisms.(26)

Thiol groups compensate reactive oxygen species (ROS) via forming disulfide bridges. In this regard, serum disulfide levels may be an indicator of metabolic oxidative stress. Accordingly, in our study, the disulfide level was significantly higher in the SpA group compared to the control group. In subgroup analyzes, disulfide level was found to be 
significantly higher in USpA compared to AS. In the USpA group, lower thiol and higher disulfide levels were found. These results may support the approach to intensifying the treatment with biological agents such as anti-TNF agents in USpA patients with active disease.

A strong negative correlation between acute phase reactants (CRP and ESR) and thiol levels may imply that thiol measurements can be used to monitor disease activity. These results seem to be consistent with other researches, which found thiol levels to be correlated with ESR and CRP levels. $(22,27)$

A positive correlation between disease duration and disulfide levels may imply that oxidative stress is a complex process that is not only triggered by acute stress but may also accumulate chronically. Recent studies also support the hypothesis that thioldisulfide counterbalance moves towards to disulfide arm in chronic inflammatory diseases course. $(28-30)$

4 Although the study has successfully demonstrated that native and total thiol levels correlate with acute phase reactants, evaluating of the variations in the thiol-disulfide levels over time could provide further information to elucidate the clinical significance of thiol-disulfide levels. This point can be account as a limitation of this study. Otherwise, we only excluded the active smokers from the study. As a potential limitation, it should be mentioned that being an ex-smoker was not assigned as an exclusion criteria which could be a minor confounder of the results.

In conclusion, thiol-disulfide balance is disturbed in favor of disulfide in SpAs. Native thiol measurement can also be used to monitor disease activity. Anti-TNF therapy, which is one of the backbone therapy in AS, may also help to control the oxidative degenerative 
Running Head: Thiol-Disulfide and Spondyloarthritis

process in SpA. To the best of our knowledge, this is the first study comparing oxidative stress in AS and USpA patients. Further studies are needed to provide new insights into disrupted thiol-disulfide homeostasis in $\mathrm{SpA}$, which may become a potential therapeutic target in the future.

Acknowledgement and conflict of interest: The authors declare that there is no conflict of interest. This study conformed to the Helsinki Declaration. The study was approved by the ethic review board from Ankara Yildirim Beyazit University Faculty of Medicine.

\section{References}

1. Rudwaleit M, Van der Heijde D, Khan M, Braun J, Sieper J. How to diagnose axial spondyloarthritis early. Annals of the rheumatic diseases. 2004;63(5):535-43.

2. Baykara RA, Tuzcu A, Omma A, Acet GK, Dogan E, Aydin A, et al. Evaluation of serum thiol/disulfide homeostasis in patients with ankylosing spondylitis by a novel method. Northern Clinics of İstanbul. 2019;6(4):348.

3. Bergamini CM, Gambetti S, Dondi A, Cervellati C. Oxygen, reactive oxygen species and tissue damage. Current pharmaceutical design. 2004;10(14):1611-26.

4. Leichert LI, Gehrke F, Gudiseva HV, Blackwell T, Ilbert M, Walker AK, et al. Quantifying changes in the thiol redox proteome upon oxidative stress in vivo. Proceedings of the National Academy of Sciences. 2008;105(24):8197-202.

5. Margaritelis NV, Veskoukis AS, Paschalis V, Vrabas IS, Dipla K, Zafeiridis A, et al. Blood reflects tissue oxidative stress: a systematic review. Biomarkers. 2015;20(2):97-108.

6. Valavanidis A, Vlachogianni T, Fiotakis C. 8-hydroxy-2'-deoxyguanosine (8-OHdG): a critical biomarker of oxidative stress and carcinogenesis. Journal of environmental science and health Part $\mathrm{C}$. 2009;27(2):120-39.

7. DiMarco T, Giulivi C. Current analytical methods for the detection of dityrosine, a biomarker of oxidative stress, in biological samples. Mass spectrometry reviews. 2007;26(1):108-20.

8. Erel O, Neselioglu S. A novel and automated assay for thiol/disulphide homeostasis. Clinical biochemistry. 2014;47(18):326-32.

9. Solmaz D, Kozacı D, İsmail Sarı AT, Önen F, Akkoç N, Akar S. Oxidative stress and related factors in patients with ankylosing spondylitis. European Journal of Rheumatology. 2016;3(1):20.

10. Karakoc M, Altindag O, Keles H, Soran N, Selek S. Serum oxidative-antioxidative status in patients with ankylosing spondilitis. Rheumatology international. 2007;27(12):1131-4.

11. Fonseca LJSd, Nunes-Souza V, Goulart MOF, Rabelo LA. Oxidative stress in rheumatoid arthritis: What the future might hold regarding novel biomarkers and add-on therapies. Oxidative Medicine and Cellular Longevity. 2019;2019.

12. Yang J, Yang X, Zou H, Li M. Oxidative stress and Treg and Th17 dysfunction in systemic lupus erythematosus. Oxidative medicine and cellular longevity. 2016;2016.

13. Bradley M, Markesbery W, Lovell M. Increased levels of 4-hydroxynonenal and acrolein in the brain in preclinical Alzheimer disease. Free Radical Biology and Medicine. 2010;48(12):1570-6.

14. Butterfield DA, Boyd-Kimball D. The critical role of methionine 35 in Alzheimer's amyloid $\beta$ peptide (1-42)-induced oxidative stress and neurotoxicity. Biochimica et Biophysica Acta (BBA)-Proteins and Proteomics. 2005;1703(2):149-56. 
15. Daiber A, Di Lisa F, Oelze M, Kröller-Schön S, Steven S, Schulz E, et al. Crosstalk of mitochondria with NADPH oxidase via reactive oxygen and nitrogen species signalling and its role for vascular function. British journal of pharmacology. 2017;174(12):1670-89.

16. Itani HA, Dikalova AE, McMaster WG, Nazarewicz RR, Bikineyeva AT, Harrison DG, et al. Mitochondrial cyclophilin D in vascular oxidative stress and hypertension. Hypertension. 2016;67(6):121827.

17. Tiwari BK, Pandey KB, Abidi A, Rizvi SI. Markers of oxidative stress during diabetes mellitus. Journal of biomarkers. 2013;2013.

18. Linden SVD, Valkenburg HA, Cats A. Evaluation of diagnostic criteria for ankylosing spondylitis. Arthritis \& Rheumatism. 1984;27(4):361-8.

19. Rudwaleit M, Van Der Heijde D, Landewé R, Listing J, Akkoc N, Brandt J, et al. The development of Assessment of SpondyloArthritis international Society classification criteria for axial spondyloarthritis (part II): validation and final selection. Annals of the rheumatic diseases. 2009;68(6):777-83.

20. Garrett S, Jenkinson T, Kennedy LG, Whitelock H, Gaisford P, Calin A. A new approach to defining disease status in ankylosing spondylitis: the Bath Ankylosing Spondylitis Disease Activity Index. The Journal of rheumatology. 1994;21(12):2286-91.

21. Sayre LM, Smith MA, Perry G. Chemistry and biochemistry of oxidative stress in neurodegenerative disease. Current medicinal chemistry. 2001;8(7):721-38.

22. Dogru A, Balkarli A, Cetin GY, Neselioglu S, Erel O, Tunc SE, et al. Thiol/disulfide homeostasis in patients with ankylosing spondylitis. Bosnian journal of basic medical sciences. 2016;16(3):187.

23. Feijóo M, Túnez I, Ruiz A, Tasset I, Muñoz E, Collantes E. Oxidative stress biomarkers as indicator of chronic inflammatory joint diseases stage. Reumatología Clínica (English Edition). 2010;6(2):91-4.

24. Il'in M, Mal'tseva P, Rosanov D, Volkova A, Khrustalev A. Changes in oxidative stress and apoptosis parameters of neutrophils in rheumatoid diseases. Zhurnal mikrobiologii, epidemiologii, $\mathrm{i}$ immunobiologii. 2012(1):89-92.

25. Olama SM, Elarman MM. Evaluation of paraoxonase and arylesterase activities in Egyptian patients with ankylosing spondylitis. Rheumatology international. 2013;33(6):1487-94.

26. Ugan Y, Nazıroğlu M, Şahin M, Aykur M. Anti-tumor necrosis factor alpha (Infliximab) attenuates apoptosis, oxidative stress, and calcium ion entry through modulation of cation channels in neutrophils of patients with ankylosing spondylitis. The Journal of membrane biology. 2016;249(4):437-47.

27. Yazici C, Kose K, Calis M, Kuzugüden S, Kirnap M. Protein oxidation status in patients with ankylosing spondylitis. Rheumatology. 2004;43(10):1235-9.

28. Emre S, Demirseren DD, Alisik M, Aktas A, Neselioglu S, Erel O. Dynamic thiol/disulfide homeostasis and effects of smoking on homeostasis parameters in patients with psoriasis. Cutaneous and Ocular Toxicology. 2017;36(4):393-6.

29. Gündüztepe Y, Bukan N, Zorlu E, Karaman Y, Topkan TA, Gurbuz N, et al. The evaluation of thioldisulfite balance, ischemıa albumın modıfıcation and seruloplazmine as a new oxidatıve stress in mild cognitive impairment and early stage alzheimer's disease patients. Journal of Clinical Neuroscience. 2020. 30. Gumusyayla S, Vural G, Bektas H, Deniz O, Neselioglu S, Erel O. A novel oxidative stress marker in patients with Alzheimer's disease: dynamic thiol-disulphide homeostasis. Acta neuropsychiatrica. 2016;28(6):315-20. 
Tables:

7 Table 1: Comparison of gender and age distribution of patient and control groups

\begin{tabular}{|l|l|c|c|c|c|}
\hline \multicolumn{2}{|c|}{} & \multicolumn{2}{|c|}{ SpA (n=144) } & Healthy & P Value \\
\cline { 2 - 4 } & $\begin{array}{c}\text { USpAn (\%) } \\
(\mathbf{n = 9 7 )}\end{array}$ & $\begin{array}{c}\text { AS n (\%) } \\
(\mathbf{n = 4 7})\end{array}$ & $\begin{array}{c}\text { Control (HC) } \\
(\mathbf{n = 8 0})\end{array}$ & \\
\cline { 1 - 4 } Sex-n-(\%) & $\mathbf{F}$ & $80(82.5)$ & $22(46.8)$ & $50(62.5)$ & 0.167 \\
\cline { 2 - 5 } & $\mathbf{M}$ & $17(17.5)$ & $25(53.1)$ & $30(37.5)$ & \\
\hline $\begin{array}{l}\text { Median age, } \\
\text { (range) }\end{array}$ & $50(23-69)$ & $46(28-66)$ & $46(24-72)$ & 0.273 \\
\hline
\end{tabular}

8

9 SpA: spondyloarthritis, USpA: undifferrentiated spondyloarthritis, AS: ankylosing 10 spondylitis, F: female, M: Male; yr: year, y: year.

12 Table 2: Comparison of USpA and AS groups in terms of disease duration, diagnosis 13 age, BASDAI score, ESR, CRP, HLAB27, and treatment. 


\begin{tabular}{|l|c|c|c|}
\hline \multicolumn{1}{|c|}{} & $\begin{array}{c}\text { USpA } \\
(\mathbf{n}=97)\end{array}$ & $\begin{array}{c}\text { AS value } \\
(\mathbf{n}=47)\end{array}$ & 0.315 \\
\hline Median dur. of disease & $7(2-12)$ & $7(1-13)$ & $\mathbf{0 . 0 1}$ \\
\hline $\begin{array}{l}\text { Mear, (range) } \\
\text { year (range) }\end{array}$ & $44.5(16-61)$ & $37.5(21-60)$ & 0.44 \\
\hline $\begin{array}{l}\text { Median BASDAI, } \\
\text { (range) }\end{array}$ & $5.5(1.3-9.3)$ & $5.6(1.4-8.4)$ & $0.144^{*}$ \\
\hline $\begin{array}{l}\text { Median ESR mm/h } \\
\text { (range) }\end{array}$ & $21.0(1-111)$ & $13(2-54)$ & $0.16^{*}$ \\
\hline $\begin{array}{l}\text { Median CRP mg/dl } \\
\text { (range) }\end{array}$ & $4.3(1-79)$ & $1(1-77)$ & 0.099 \\
\hline HLA-B27 n (\%) & $15(30.6)$ & $9(52.9)$ & \\
\hline
\end{tabular}

USpA: undifferrentiated spondyloarthritis; AS: ankylosing spondylitis;

3 BASDAI: Bath Ankylosing Spondylitis Disease Activity Index; ESR: erythrocyte

4 sedimentation rate; CRP: C-reactive protein; HLA B27: Human leucocyte antigen;

5 NSAID: non-steroid anti-inflammatory drugs; dur: duration, diag; diagnosis 
1 Table 3: Comparison of Dynamic Thiol-Disulfide Values between patients and healthy 2 individuals

\begin{tabular}{|c|c|c|c|c|}
\hline & $\begin{array}{c}\text { USpA } \\
(n=97) \\
\text { mean (SD) }\end{array}$ & $\begin{array}{c}\text { AS } \\
(n=47) \\
\text { mean (SD) }\end{array}$ & $\begin{array}{c}\text { Healthy control }(\mathrm{HC}) \\
\qquad(\mathbf{n}=\mathbf{8 0}) \\
\text { Mean }(\mathrm{SD})\end{array}$ & P value* \\
\hline NT, $\mu \mathrm{mol} / \mathrm{L}$ & $432,4( \pm 41,0)$ & $455,6( \pm 48,1)$ & $468,1( \pm 43,1)$ & $<0.001$ \\
\hline $\mathrm{TT}, \mu \mathrm{mol} / \mathrm{L}$ & $476,6( \pm 41,1)$ & $490,6( \pm 52,8)$ & $492,3( \pm 41,1)$ & 0.074 \\
\hline Disulfide, $\mu \mathrm{mol} / \mathrm{L}$ & $22,1( \pm 7,0)$ & $17,5( \pm 9,2)$ & $12,0( \pm 6,0)$ & $<0.001$ \\
\hline D/NT & $5,1( \pm 1,8)$ & $3,8( \pm 2,0)$ & $2,6( \pm 1,4)$ & $<0.001$ \\
\hline D/TT & $4,6( \pm 1,4)$ & $3,5( \pm 1,7)$ & $2,4( \pm 1,2)$ & $<0.001$ \\
\hline $\begin{array}{l}\text { NT/TT } \\
\end{array}$ & $90,6( \pm 2,9)$ & $92,9( \pm 3,4)$ & $95( \pm 2,5)$ & $<0.001$ \\
\hline
\end{tabular}

4

5 USpA: undifferrentiated spondyloarthritis; AS: ankylosing spondylitis; NA: not

6 applicable

7 NT: native thiol; TT: total thiol; D/NT: disulfide/native thiol; D/TT: disulfide/total thiol;

8 NT/TT: native thiol/total thiol

$9 \quad * \mathrm{P}$ value is obtained from One-Way ANCOVA, after eliminating the gender effect. 
Table 4: Pairwise Comparison of Dynamic Thiol-Disulfide Values between groups

\begin{tabular}{|c|c|c|c|c|}
\hline & & $\begin{array}{l}\text { UspA } \\
(\mathbf{n}=97)\end{array}$ & $\begin{array}{c}\text { AS } \\
(n=47)\end{array}$ & $\begin{array}{l}\text { Healthy control (HC) } \\
\qquad(\mathrm{n}=\mathbf{8 0})\end{array}$ \\
\hline \multirow{3}{*}{$\mathrm{NT}, \mu \mathrm{mol} / \mathrm{L}$} & USpA & NA & $P=0.021$ & $P<0.001$ \\
\hline & $\mathbf{A S}$ & $P=0.021$ & $\mathrm{NA}$ & $\mathrm{P}=0.304$ \\
\hline & HC & $P<0.001$ & $\mathrm{P}=0.304$ & NA \\
\hline \multirow{3}{*}{$\mathrm{TT}, \boldsymbol{\mu m o l} / \mathrm{L}$} & USpA & NA & $\mathrm{P}=0.244$ & $\mathrm{P}=0.071$ \\
\hline & $\mathbf{A S}$ & $\mathrm{P}=0.244$ & $\mathrm{NA}$ & $\mathrm{P}=0.978$ \\
\hline & HC & $\mathrm{P}=0.071$ & $\mathrm{P}=0.978$ & NA \\
\hline \multirow{3}{*}{$\begin{array}{l}\text { Disulfide, } \\
\text { Mmol/L }\end{array}$} & USpA & $\mathrm{NA}$ & $P=0.004$ & $P<0.001$ \\
\hline & $\mathbf{A S}$ & $P=0.004$ & $\mathrm{NA}$ & $P<0.001$ \\
\hline & $\mathrm{HC}$ & $P<0.001$ & $P<0.001$ & NA \\
\hline \multirow{3}{*}{$\mathrm{D} / \mathrm{NT}$} & USpA & NA & $P<0.001$ & $P<0.001$ \\
\hline & $\mathbf{A S}$ & $P<0.001$ & $\mathrm{NA}$ & $P<0.001$ \\
\hline & HC & $P<0.001$ & $P<0.001$ & NA \\
\hline \multirow{3}{*}{ D/TT } & USpA & NA & $P<0.001$ & $P<0.001$ \\
\hline & $\mathbf{A S}$ & $P<0.001$ & NA & $P<0.001$ \\
\hline & $\mathrm{HC}$ & $P<0.001$ & $P<0.001$ & NA \\
\hline \multirow{3}{*}{ NT/TT } & USpA & NA & $P<0.001$ & $P<0.001$ \\
\hline & $\mathbf{A S}$ & $P<0.001$ & NA & $P<0.001$ \\
\hline & HC & $P<0.001$ & $P<0.001$ & NA \\
\hline
\end{tabular}

3

4 USpA: undifferrentiated spondyloarthritis; AS: ankylosing spondylitis; NA: not

5 applicable

6 NT: native thiol; TT: total thiol; D/NT: disulfide/native thiol; D/TT: disulfide/total thiol;

$7 \quad$ NT/TT: native thiol/total thiol. 
1 The P value is obtained from one-way ANCOVA with Bonferroni correction test for each

2 pairwise comparison. (Gender effect is eliminated)

3 Table 5: The Results of correlation analysis between dynamic thiol-disulfide parameters 4 and BASDAI score, disease duration, CRP, ESR.

\begin{tabular}{|c|c|c|c|c|c|c|c|}
\hline & & $\begin{array}{c}\text { NT } \\
\mu \mathrm{mol} / \mathrm{L}\end{array}$ & $\begin{array}{c}\text { TT } \\
\mu \mathrm{mol} / \mathrm{L}\end{array}$ & $\begin{array}{c}\text { Disulfide } \\
\mu \mathrm{mol} / \mathrm{L}\end{array}$ & $\begin{array}{c}\mathrm{D} / \mathrm{NT} \\
\%\end{array}$ & $\begin{array}{c}\text { D/TT } \\
\%\end{array}$ & $\begin{array}{c}\text { NT/TT } \\
\%\end{array}$ \\
\hline BASDAI & \begin{tabular}{|l|}
$\begin{array}{l}\text { Correlation } \\
\text { coefficient }\end{array}$ \\
\end{tabular} &,- 092 &,- 077 & ,113 &, 142 & , 142 &,- 142 \\
\hline & $p$ value & ,374 & ,458 & ,274 & , 166 & , 166 & , 166 \\
\hline & $\mathrm{n}$ & 96 & 96 & 96 & 96 & 96 & 96 \\
\hline $\begin{array}{l}\text { Disease } \\
\text { duration; }\end{array}$ & $\begin{array}{l}\text { Correlation } \\
\text { coefficient }\end{array}$ & ,113 & 025 &,$- 196^{*}$ &,$- 192^{*}$ &,$- 192^{*}$ &, $192^{*}$ \\
\hline & $\mathrm{p}$ value & ,236 & ,792 & ,039 & ,043 & ,043 & ,043 \\
\hline & $\mathrm{n}$ & 111 & 111 & 111 & 111 & 111 & 111 \\
\hline CRP; mg/dl & $\begin{array}{l}\text { Correlation } \\
\text { coefficient }\end{array}$ &,$- 345^{* *}$ &,$- 308^{* *}$ & ,083 & , 137 & , 137 &,- 137 \\
\hline & $p$ value & ,000 & ,001 & ,381 & , 151 & , 151 & , 151 \\
\hline & $\mathrm{n}$ & 112 & 112 & 112 & 112 & 112 & 112 \\
\hline ESR; mm/h & $\begin{array}{l}\text { Correlation } \\
\text { coefficient }\end{array}$ &,$- 396^{* *}$ &,$- 351^{* *}$ & ,086 & ,164 & ,164 &,- 164 \\
\hline & $p$ value & ,000 & ,000 & ,371 & ,085 & ,085 & ,085 \\
\hline & $\mathrm{n}$ & 111 & 111 & 111 & 111 & 111 & 111 \\
\hline
\end{tabular}

6

7 BASDAI: Bath Ankylosing Spondylitis Disease Activity Index; ESR: erythrocyte

8 sedimentation rate; CRP: C-reactive protein; 
1 NT: native thiol; TT: total thiol; D/NT: disulfide/native thiol; D/TT: disulfide/total thiol;

2 NT/TT: native thiol/total thiol.

4 Table 6. Comparison of thiol-disulfide parameters according to treatment modality in 5 patients with SpA.

\begin{tabular}{|c|c|c|c|}
\hline & $\begin{array}{c}\text { Anti-TNF } \\
(n=38)\end{array}$ & $\begin{array}{c}\text { cDMARD+NSAIDs } \\
(n=106)\end{array}$ & $\begin{array}{c}\mathbf{P} \\
\text { Value* }\end{array}$ \\
\hline $\begin{array}{l}\text { Native thiol, } \mu \mathrm{mol} / \mathrm{L} \text {, } \\
\operatorname{mean}(\mathrm{SD})\end{array}$ & $450(57.1)$ & $436(38.5)$ & 0.001 \\
\hline $\begin{array}{l}\text { Total thiol, } \mu \mathrm{mol} / \mathrm{L} \text {, } \\
\text { mean }(\mathrm{SD})\end{array}$ & $495(56.3)$ & $476(39.9)$ & 0.007 \\
\hline 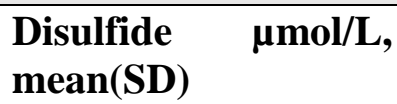 & $22.1(9.3)$ & $19.8(7.5)$ & 0.062 \\
\hline D/NT, \%, mean(SD) & $5.0(2.3)$ & $4.6(1.8)$ & 0.155 \\
\hline $\mathrm{D} / \mathrm{T}, \%, \operatorname{mean}(\mathrm{SD})$ & $4.4(1.9)$ & $4.1(1.5)$ & 0.171 \\
\hline NT/TT, \%, mean(SD) & $91.0(3.8)$ & $91.6(3.0)$ & 0.171 \\
\hline
\end{tabular}

7 
$4 \quad$ Table 7: Patient groups according to treatment characteristics.

\begin{tabular}{|c|c|c|c|}
\hline Treatment & $\begin{array}{c}\text { Anti-TNF n(\%) } \\
\quad(n=38)\end{array}$ & $\begin{array}{c}\text { CDMARD+NSAID } \\
(n=106)\end{array}$ & $\mathbf{P}$ \\
\hline Age, year (SD) & $46( \pm 12)$ & $48.9( \pm 8.9)$ & $0.134 * *$ \\
\hline \begin{tabular}{|ll} 
Sex & K \\
& E
\end{tabular} & $\begin{array}{l}18(47.4) \\
20(52.6)\end{array}$ & $\begin{array}{l}85(80.2) \\
21(19.8)\end{array}$ & $<0.0001 *$ \\
\hline \begin{tabular}{|rr} 
SpA & AS \\
& SpA
\end{tabular} & $\begin{array}{l}20(52.6) \\
18(47.4)\end{array}$ & $\begin{array}{l}27(25.5) \\
79(74.5)\end{array}$ & $0.002 *$ \\
\hline
\end{tabular}

5

6 USpA: undifferrentiated spondyloarthritis; AS: ankylosing spondylitis, NSAID: non-

7 steroid anti-inflammatory drug; cDMARD: conventional disease-modifying anti-

8 rheumatic drug, anti-TNF: anti-tumor necrosis factor, * Chi-Square Test, ** Student T-

9 Test, 